\title{
Acoustic Emissions in Fracturing Sea Ice Plate Simulated by Particle System
}

\author{
By Zhengzhi Li ${ }^{1}$ and Zdeněk P. Bažant, ${ }^{2}$ Fellow, ASCE
}

\begin{abstract}
In-plane dynamic fracture jumps and acoustic emissions in sea ice floes of different sizes are simulated by the particle system. Fracture patterns and time sequences similar to those observed in experiments are achieved. For the given spatial location of hydrophone, the acoustic signals from crack jumps in ice are calculated in the frequency domain by a modified Farmer and Xie's acoustic model for ice plate floating in shallow sea. The acoustic pressure-time histories are synthesized by the Fourier inverse transform. The calculated acoustic signals resemble the recorded signals. Their overall character is found to depend on the plate size. This is a size effect that is manifested in the calculated root-mean-square history of the acoustic pressure at hydrophone. Differences among the acoustic records for different fracture lengths are found. They offer the possibility of making inferences on the fracture characteristics of sea ice from the acoustic records.
\end{abstract}

\section{INTRODUCTION}

There are many problems in which large-scale failure of floating sea ice plates needs to be analyzed and predicted. They include the load-carrying capacity for heavy objects placed on the ice plate and vertical penetration through the plate from above as well as from below; the forces exerted by a moving ice plate on a rigid obstacle such as an oil drilling platform or bridge pier; formation of long fractures in the Arctic Ocean triggering the formation of large open water leads, pressure ridges, and rafting zones; the breakup ice floes in collisions; the technology of ice breaking; etc.

Until recently, these problems were analyzed either on the basis of elasticity and creep or on the basis of plasticity, even though it has been known that microscopically the material failure consists of cracking. It was believed that fracture mechanics was inapplicable because laboratory tests and smallscale tests in the field indicated negligible notch sensitivity. However, from the studies of size effect and scaling law, it recently became clear that the behavior on a large scale ought to be different and ought to follow fracture mechanics. The reason is that the size effect in sea ice, as a material with large inhomogeneities, is transitional between plasticity and linear elastic fracture mechanics, with plasticity approached at small sizes and linear elastic fracture mechanics approached at very large sizes. This behavior is typical of all quasi-brittle materials, which also include concrete, rock, and various advanced composites and ceramics.

In this light, systematic studies of sea ice fracture, with a focus on the large-scale behavior, have been initiated and carried out at Clarkson University (Dempsey et al. 1991, 1992, 1995; Dempsey and Zhao 1993) and Northwestern University (Bažant and Kim 1985; Bažant 1992a,b; Bažant and Li 1993, 1994, 1995; Jirásek and Bažant, 1993, 1995a,b; Li and Bažant 1994; Bažant et al. 1995a,b). Recently, a large-scale in-situ fracture testing program, in which floating sea ice specimens of sizes up to $80 \times 80$ have been tested in the Arctic Ocean, has been organized by Dempsey [see Adamson et al. (1995), Mulmule et al. (1995), Dempsey et al. (1995, 1996). These experiments have exploited observations of the size effect as

\footnotetext{
'Grad. Res. Asst., Dept. of Civ. Engrg., Northwestern Univ., Evanston, IL 60208 .

${ }^{2}$ Walter P. Murphy Prof, of Civ. Engrg. and Mat. Sci., Northwestern Univ., Evanston, IL.

Note. Associate Editor: Dimitrios Karamanlidis. Discussion open until June 1,1998 . To extend the closing date one month, a written request must be filed with the ASCE Manager of Journals. The manuscript for this paper was submitted for review and possible publication on April 4 1996. This paper is part of the Journal of Engineering Mechanics, Vol. 124, No. 1, January, 1998. CASCE, ISSN 0733-9399/98/0001-0069$0079 / \$ 4.00+\$ .50$ per page. Paper No. 12968
}

a means of extracting large-scale fracture properties. They confirm that sea ice failure indeed follows fracture mechanics, but only at very large scales. This makes the fracture testing of sea ice extremely difficult and expensive. Therefore, it is crucial to extract from each test as much information as possible. For these reasons, the field experiments organized by Dempsey included not only force-deflection measurements but also highspeed camera-records and acoustic emission monitoring.

The monitoring of acoustic signals can be useful in various ways. If a sufficient number of hydrophones are used, the first arrival times can reveal the locations of the microfracture events causing the acoustic emissions. This makes it possible to determine the size and shape of the fracture process zone. Furthermore, from the time history of the recorded emission, even that received by a single hydrophone, one should be able to make useful judgments about the history of the fracture process. The present paper will focus on this last problem.

To extract useful information from the time history of acoustic emissions, it is necessary to model the fracture process of a specimen of sea ice in such a manner that individual microcracks are simulated as distinct events and then calculate the path of the acoustic waves emitted toward the hydrophone. Study of this problem is the objective of the present paper. However, the inverse problem of inferring the ice fracture behavior and basic properties from the acoustic emissions will be beyond the scope of the present paper.

Acoustic waves in floating sea ice sheets have been studied extensively and important results have been achieved. Press and Ewing (1951) developed the classical theory of such waves. In analyzing the waves produced by formations of cracks in an ice sheet, the acoustic signals transmitted by multipath waves toward a hydrophone have been analyzed (Stein 1988; Farmer and Xie 1989). These waves consist of the direct acoustic wave ( $A$-wave); reflected acoustic wave ( $R$-wave), longitudinal wave ( $P$-wave), and flexural wave ( $F$-wave), which leak from the ice sheet into the seawater [Figs. 1(a and b)].

In the present study, the advanced model of Farmer and Xie (1989) is adopted and modified as the basis of the acoustic wave calculations. In this model, the propagating crack in the ice floe is described as a moving monopole point source, and the acoustic wave is calculated according to Haskell (1964) considering a sinusoidally roughened ramp function. The acoustic signals, which are produced by the individual cracking events and simulated according to Farmer and Xie (1989), are superimposed in the time domain.

Most of the power of the acoustic signal received is known to come from the $A$-wave and $R$-wave, whereas the $P$-wave contribution appears insignificant. It represents only about $0.2 \%$ of the power transmitted by the $A$-wave, according to Xie and Farmer (1989). 


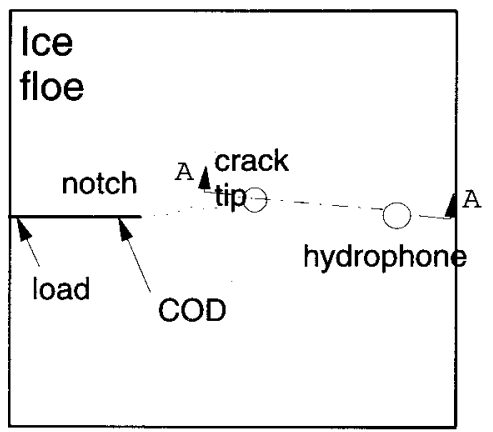

(a)

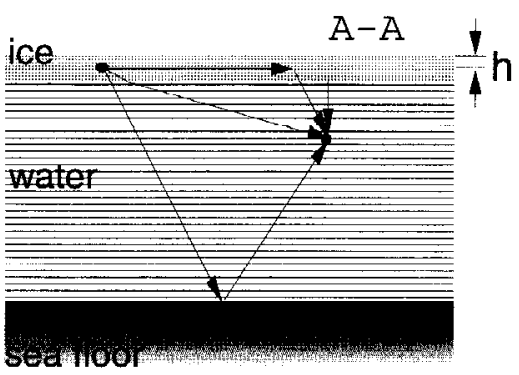

(b)

FIG. 1. (a) Types of Acoustic Emissions from Ice Sheet Fracture; (b) Wave Propagation Path and Receiver Position (A-Wave, $\boldsymbol{R}$-Wave, $P$-Wave, and $F$-Wave)

\section{SIMULATION OF ICE FRACTURE TEST BY RANDOM PARTICLE SYSTEM}

So far the analytical solution for arbitrary dynamic fracture is unavailable, especially for quasi-brittle inhomogeneous materials with grains. Finite-element modeling is a rather difficult proposition, which requires a nonlocal approach. Even then, it is hardly possible to simulate the formation of numerous individual cracks that serve as the sources of the acoustic emissions. Simulation by a random particle system, which is a special case of the discrete element method, is much more suitable for this purpose.

The discrete element method was first developed for granular solids (Cundall 1971; Cundall and Strack 1979). Introducing tensile interparticle forces with a postpeak sudden or gradual stress drop, Zubelewicz and Bažant (1987) adapted this model to the fracture of concrete. This model was later modified and refined by Bažant et al. (1990). Recently, Jirásek and Bažant (1995a,b) developed a dynamic version of this model and applied it to the simulation of impact of an ice floe on a fixed obstacle. They also developed a very efficient explicit time-step method of numerical integration, with which systems with over 120,000 degrees of freedom have been successfully handled [see Jirásek and Bažant (1995a), who give a detailed description of the model and integration method].

In applications to sea ice, the particles of the model do not actually simulate any real particles in the material. Rather, the particle system represents a convenient means of imposing nonlocal characteristics on the macroscopic evolution of damage. The particle structure prevents localization of fracture and thus of the energy dissipation zone into a region whose thickness is smaller than the mean spacing of the particles. The particle model can ensure that a certain fixed minimum amount of energy be dissipated for a sudden advance of the fracture. It also can ensure that a sizable blunting zone of distributed microcracking, representing a fracture process zone, develops at the front of a propagating major fracture. These two characteristics are difficult to achieve with strictly continuum type models.
The deformation properties of the material are characterized in terms of the prescribed relationship between the interparticle force and relative displacement. In contrast to the initial model of Zubelewicz and Bažant (1987), transmission of shear forces between the particles and the rotations of particles are ignored, for the sake of simplicity, which means that the particle model is in effect equivalent to a truss. As established in previous studies, taking interparticle shear into account has the effect of widening and extending the fracture process zone, but programming of the model, which must include the moment conditions of equilibrium of the particles, with particle rotations as degrees of freedom in addition to particle displacements, becomes more complicated. Subsequent studies (Bažant et al. 1990; Jirásek and Bažant 1995a,b) show that about the same result can be achieved by assuming a larger coefficient of variation of the interparticle strength and replacing vertical (or steep) postpeak softening of the interparticle force-displacement relation by softening of a milder slope. The penalty to pay for the simplification of programming is the need to use a greater number of degrees of freedom, but this is becoming less of a problem as the power of desk top computers is increasing.

The interparticle force-displacement relation was characterized by microtensile strength $f_{t}^{m}=0.4 \mathrm{MPa}$, microelastic modulus 5,000 MPa, and a triangular (bilinear) force-displacement relation in which the ratio of the average strain of interparticle link at force reduction to zero (the breaking strain) $\varepsilon_{f}$, to the strain $\varepsilon_{p}$ at peak force was 1.2. The area under the interparticle force-displacement curve represents the microfracture energy $G_{f}^{m}$, which can be related to the macrofracture energy $G_{f}$ on the basis of the Bažant's size effect law, as described in Jirásek and Bažant (1993, 1995a,b). The interparticle microcompression strength was taken as $f_{c}^{m}=6 f_{t}$ and a nonzero residual strength was assumed to exist in compression, as shown in Fig. 2. The damping of the material was taken into account by a viscous stress proportional to the strain rate. It may be noted that the relationship of micro- and macrofracture energies also depends on the ratio $\varepsilon_{f} / \varepsilon_{p}$, on the coefficient of variation of this ratio, and the coefficient of variation of the macrostrength, as well as on the geometry of the particle configurations (Jirásek and Bažant 1995b).

The particle system is generated randomly with the help of random number generator, in a manner that ensures macroscopic statistical isotropy. In the random particle generation, the minimum distance $L_{\min }$ between particles has been specified as $0.75 \mathrm{~m}$ and the maximum distance $L_{\max }$ at which the particles still interact as $1.5 \mathrm{~m}$. The mean $\bar{L}=\left(L_{\min }-L_{\max }\right) / 2$ as well as the range $L_{\max }-L_{\min }$ has a considerable influence on the macroscopic fracture characteristics. The effective cross sections of the interparticle connections have been determined from particle distance $L_{1}$ in the way described in Jirásek and Bažant (1993, 1995a). The typical particle spacing also decides

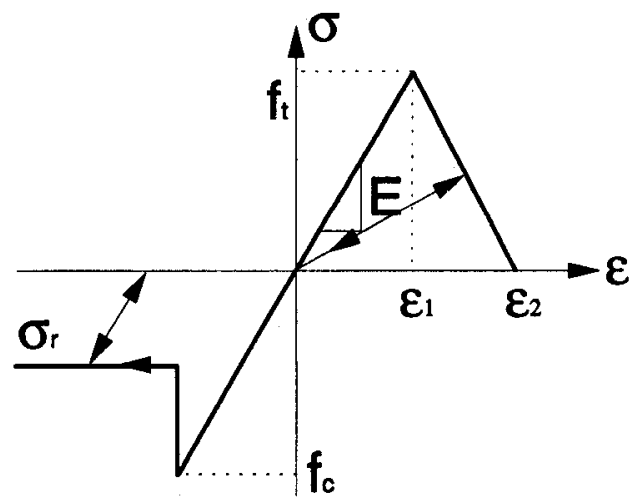

FIG. 2. Constitutive Curve for Interparticle Forces Simulating Ice 
the typical length of the microcracks (or crack jumps) that can be simulated with the particle system.

The randomness of the particle system is an important feature. Jirásek and Bažant (1993, 1995a) studied the break up of a circular ice floe in which the particle system represented a regular square lattice. The cross sections of the interparticle links along the lines of a square mesh and along the diagonal directions were chosen so as to achieve elastic isotropy. Similarly, the strengths of these two types of links were chosen so as to achieve strength isotropy with respect to straightline cuts of different orientations. Also, the postpeak slopes of the interparticle force-deflection diagrams for the two directions were chosen so that the energy dissipated per unit length by complete break along a straight-line cut would be the same for any orientation of the cut. In spite of these isotropic properties, it was found that the overall fracture propagation direction was strongly biased to the direction of the mesh lines or diagonals. Simulating the impact of a circular floe on a rigid obstacle (Jirásek and Bažant 1993, 1995a), the regular square lattice was rotated against the direction of impact of the circular floe and very different responses were obtained after ro-
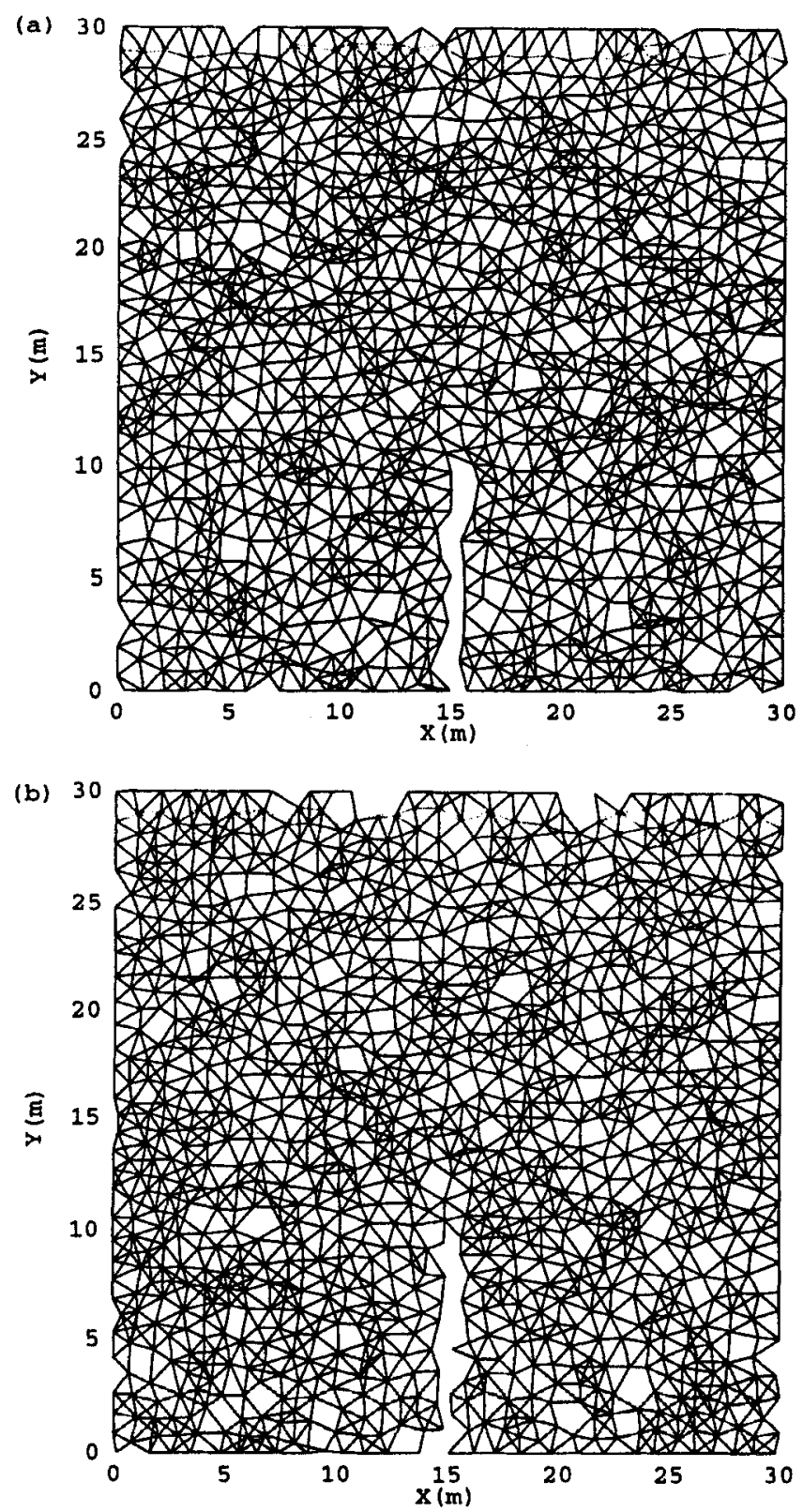

FIG. 3. Examples of Two Random Particle Model Meshes for Ice Sheet tations by various angles. On the other hand, when the particle system was random, essentially the same overall response was obtained after rigid body rotations of the particle system within the circular floe. It thus becomes clear that material isotropy for fracture propagation can be ensured only with a randomly generated particle system.

The fracture characteristics of the particle model have considerable influence on the simulated acoustic records to be discussed later. Varying these characteristics, it is possible to find an acoustic record that matches the actual record in the field best. In this manner, considerable information about the fracture process can be extracted.

The particle model is used to simulate fracture caused by in-plane loading from a notch. In the tests organized and directed by $J$. Dempsey, floating square specimens of side $L$, with a symmetrically located notch of length $a_{0}$, are cut from a floating ice plate of thickness $1.75 \mathrm{~m}$. Thus a fracture specimen of compact-tension type is obtained. A flat jack is inserted into the notch near the mouth of the notch, and its expansion is produced hydraulically by a closed-loop loading system. The loading is controlled by crack-tip opening dis-
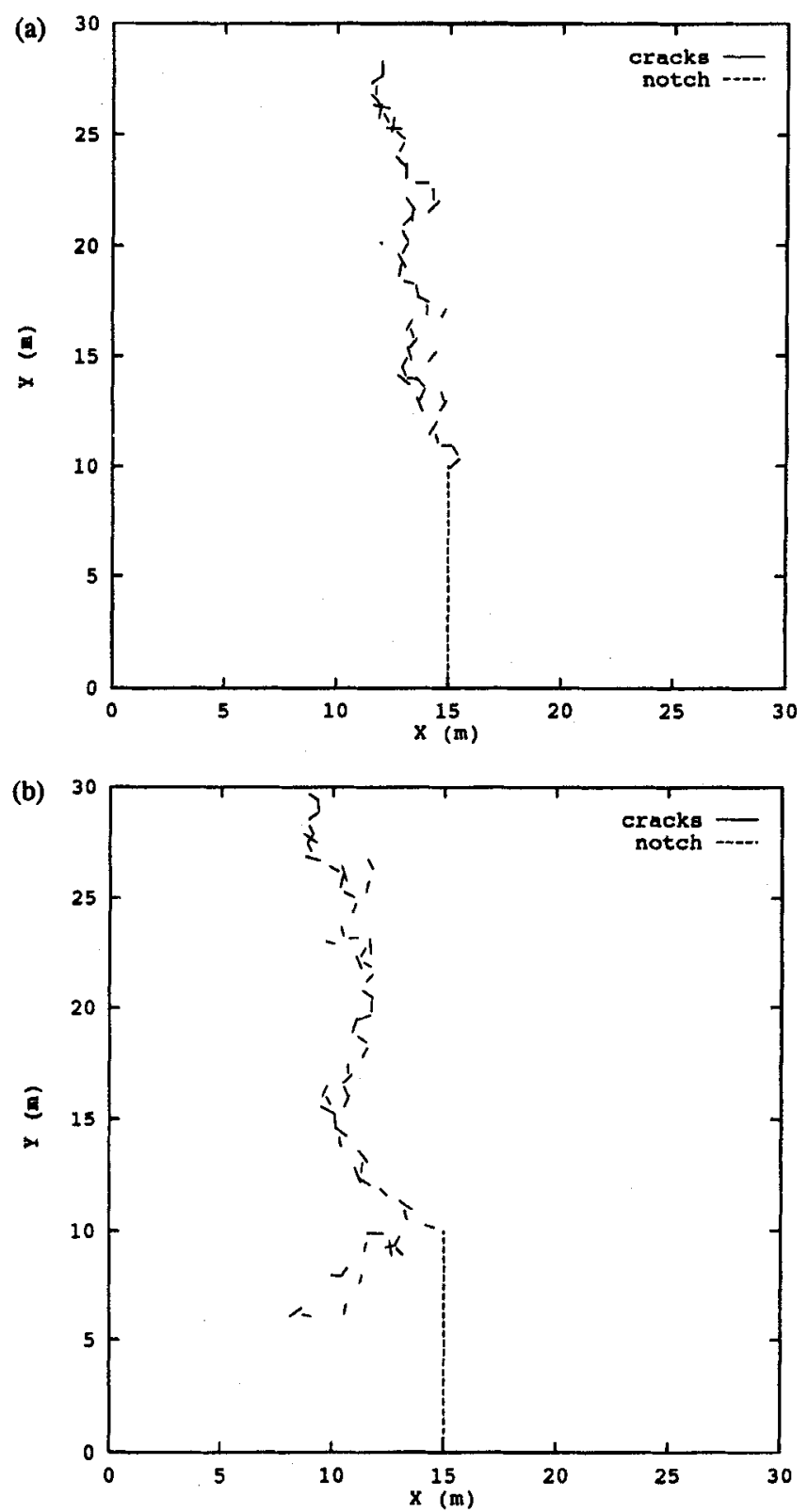

FIG. 4. Two Examples of lce Sheet Fracture Pattern (Broken Links) Calculated by Particle Model

JOURNAL OF ENGINEERING MECHANICS / JANUARY 1998 / 71 
placement (COD) at distance $a_{0} / 5$ from the notch mouth [Fig. 1(a)]. In the particular test simulated here, the side of the square specimen is $30 \mathrm{~m}$ and the notch length is $10 \mathrm{~m}$. The fracture specimen is treated as a two-dimensional particle system in a plane stress state, consisting of 1,024 randomly generated particles with 3,980 interparticle links and 2,048 degrees of freedom (see Fig. 3). The acoustic emissions are monitored by one hydrophone located on the line of symmetry, $1.75 \mathrm{~m}$ from the edge of the specimen opposite to the notch, and $5 \mathrm{~m}$ deep in the sea water [in Fig. 1(b)].

\section{DYNAMIC ANALYSIS BY EXPLICIT INTEGRATION}

The system of the equations of motion of the individual particles is solved by the well-known explicit integration algorithm based on the central difference approximation

$$
\mathbf{u}_{i+1}=2 \mathbf{u}_{i}-\mathbf{u}_{i-1}+(\Delta t)^{2} \mathbf{M}^{-1}\left(\mathbf{f}_{i}^{\mathrm{ext}}-\mathbf{f}_{i}^{\mathrm{Int}}\right)
$$

Here $\mathbf{u}=$ column matrix (vector) of all the displacement components of all particles; $\Delta t=t_{i+1}-t_{i} ; t_{i}=$ chosen discrete times (subscript $i$ refers to time $t_{i}, i=1,2,3, \ldots$ ); $\mathbf{f}_{i}^{\text {ext }}, f_{i}^{\text {int }}=$ vectors of externally applied forces and internal resisting forces acting on the particles at time $t_{i}$, associated with $\mathbf{u}_{i}$; and $\mathbf{M}=$ mass matrix of the system (a square matrix). The vector $f^{\text {int }}$ is calculated from the change of distance between the in teracting particles, by summing the vectors of the forces from all the particles interacting with a given particle. The mass matrix is considered to be lumped, and thus the component equations in (1) become formally decoupled, although in effect they still remain coupled through the calculation of $\mathbf{f}^{\text {int }}$. For the lumped mass matrix, no storage of the components of $\mathbf{M}^{-1}$ is necessary, and so the computation is the most efficient. In this way, a very large number of particles can be handled.

The maximum time step $\Delta t$ admissible for numerical stability is determined by the minimum travel time of the longitudinal wave along the interparticle link from one particle to the next. For the minimum distance $0.75 \mathrm{~m}$ between particles and the longitudinal wave velocity in ice $2,745 \mathrm{~m} / \mathrm{s}$, the maximum time step is obtained as $0.0003 \mathrm{~s}$. Because an acoustic record of $12 \mathrm{~s}$ duration is to be calculated, 40,000 time steps are needed (for this number of time steps and a system with 2,048 degrees of freedom, the computer time on an HewlettPackard (HP) workstation was about $2 \mathrm{~h}$ ).
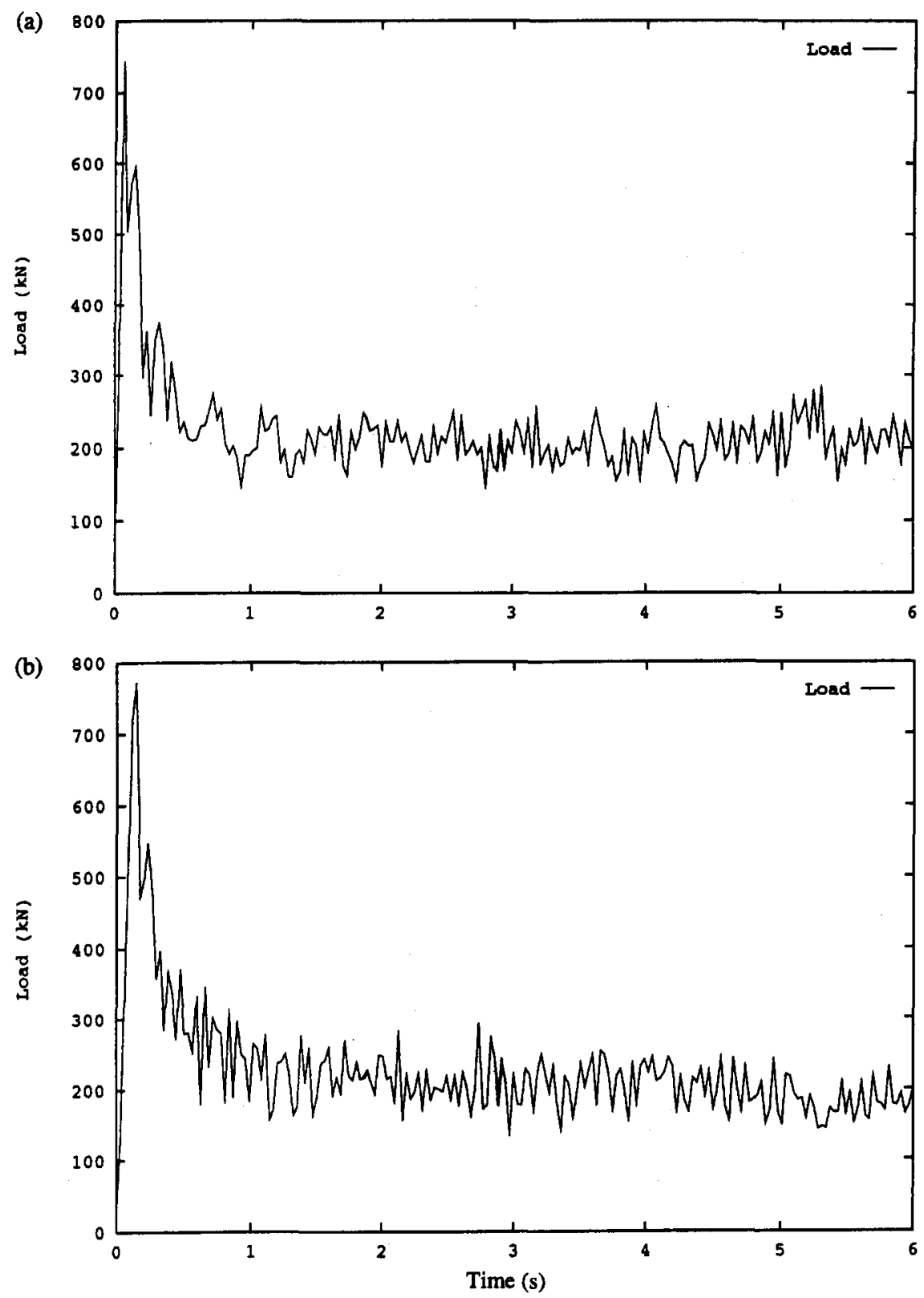

FIG. 5. Two Examples of Calculated Load Time Histories 
Several particle systems simulating the fracture specimens are randomly generated, as shown in Figs. 3( $a$ and $b$ ). Figs. $4(a$ and $b)$ show the crack patterns at the moment when the applied load $P$ has been reduced to about $50 \%$ of its maximum value [in Fig. 5(a)].

As in Dempsey's field tests in the Arctic Ocean, the COD rate is prescribed as a linear function of time (Fig. 6).

The COD was measured at the distance $\Delta x=0.2 a_{0}$ from the notch tip. Because the point of control of the COD rate differs from the resultant of loading by the flat jack, some difficulty arises in precise numerical simulation of the dynamic loading. The problem is that a load change at the loading point will affect the COD only several integration steps later, with a delay not less than the time of travel of the longitudinal wave from the center of the jack to the point of COD control. This makes it impossible to control the calculated COD precisely, but the same is of course true of the actual test.

In the present simulation, a rather close control of the COD is achieved by assuming the displacements at the loading point and the COD control point to be related as in the first free vibration mode of the specimen. This mode was calculated approximately, considering the specimen as a double cantilever specimen. Because the cantilever beams are very deep, the relative deflection of the beams between the load control point and the COD control point may be attributed mainly to shear deformation. Thus, the crack faces are assumed to remain approximately straight all the way to the crack tip. In this calculation, the crack-tip location is updated according to the fracture growth. Figs. 5( $a$ and $b$ ) show the load and the COD histories achieved in this kind of simulation. As seen from Fig. 6, a nearly linear time history of COD has been achieved. During the initial stage, there are moments at which sudden breaks of the interparticle links cause vibrations of the specimen. This is of course commonly seen in experiments as well.

The particle simulation, which is two-dimensional, yields directly only the locations and times of the crack jumps (breaks of links). To calculate the acoustic signals received at the hydrophone in water below the ice plate, the wave propagation in the ice-water-seafloor system needs to be analyzed.
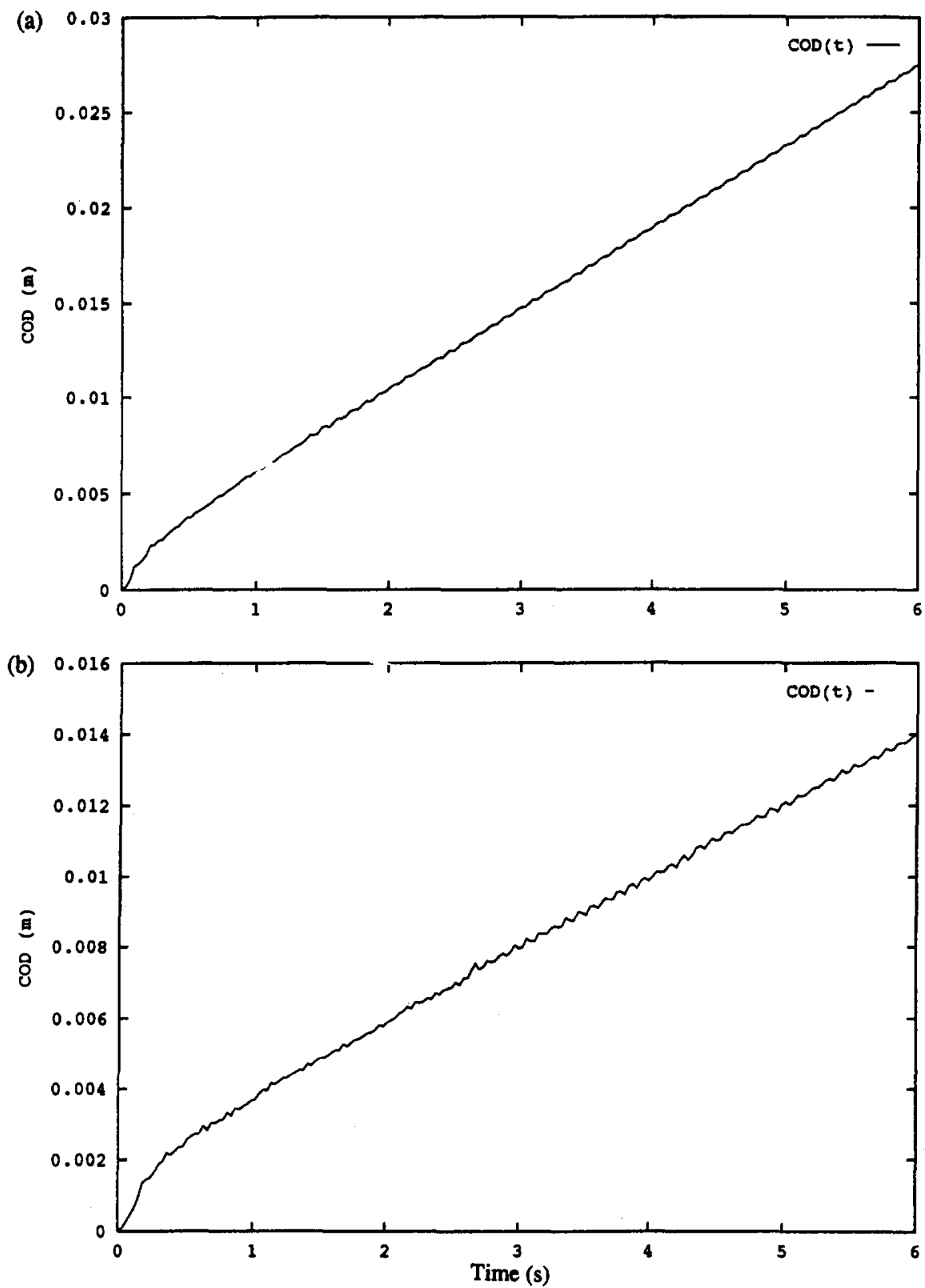

FIG. 6. Calculated Crack Opening Time Histories for the Two Examples from Fig. 5 


\section{ANALYSIS OF ACOUSTIC EMISSIONS}

Previous studies of acoustic emissions produced by cracking in sea ice sheets (Stein 1988; Farmer and Xie 1989; Xie and Farmer 1991; Xie 1994) show that the acoustic waves are mainly of four different types, namely the $A$-wave, $R$-wave, $P$-wave, and $F$-wave. The proportion of each type varies with the crack type and the loading direction. As part of the aforementioned field tests organized by Dempsey at Resolute Bay, Xie (1994), in collaboration with Farmer, recorded the acoustic emissions during the fracture process. As expected, the fracture process was seen to consist of many isolated cracking events or microcrack formations confirming that the fracture propagates in a process of jumps and arrests. Xie concluded that the crack jumped at a speed of about $430 \mathrm{~m} / \mathrm{s}$ and the length of each jump was less than $4 \mathrm{~m}$. A fracturing process with such characteristics can be described by the random particle model quite well.

The break of each link in the random particle system, which is considered equivalent to a crack jump, emanates an acoustic wave. What the particle model gives out directly is the discretized acoustic emission signal by the individual broken link. To obtain a continuous acoustic wave, the crack propagation represented by each crack jump must be taken into account.

Farmer and Xie (1989) described the acoustic waves radiated from propagating cracks in ice in a continuous manner. They used the same wave equation as Press and Ewing (1951) did for a layered elastic half-space. To represent the wave propagation in seawater, they used the velocity potential $\Phi_{2}(r$, $z, t)=\int_{0}^{\infty} \phi_{2}(r, z, \omega) e^{j \omega t} d \omega$ where $t=$ time; $r$ and $z=$ cylindrical coordinates with axis $z$ oriented downward from the midplane of ice plate, and radial distance $r$ measured along the ice plate [Fig. 7(a)]; $\phi_{2}=$ function of $z, r$, and circular frequency $\omega(i$ $=$ imaginary unit); $\varphi_{2}$ is the solution of the Helmholtz equation obtained from the wave equation after separation of variables.

Farmer and Xie (1989) described the acoustic pressure produced in the water on a propagating ice crack in the form of Fourier spectrum for the case of a two-layer half-space. By Fourier inverse transform, the acoustic pressure wave can be obtained. To get a complete analytical model, all the waves $A$, $R, P$, and $F$ should be included in the analysis. But some necessary simplifying assumptions and the asymptotic method of the solution exclude certain nonlinear and disperse parts of the wave signals. In Farmer and Xie's model, the seafloor boundary was not considered. In the present simulation, the seafloor must be taken into account, for the water depth is only about $30 \mathrm{~m}$. Hence, Farmer and Xie's model needs to be modified to a three-layer half-space [Figs. 7( $a$ and $b$ )].

The Helmholtz equations in cylindrical coordinates for the three layers are

$$
\frac{1}{r} \frac{\partial}{\partial r}\left(r \frac{\partial \phi_{j}}{\partial r}\right)+\frac{\partial^{2} \phi_{j}}{\partial z^{2}}+k_{j}^{2} \phi_{j}= \begin{cases}-4 \pi \delta(r, z-h) & \text { for } j=1 \\ 0 & \text { for } j=2,3\end{cases}
$$

where $j=1=$ ice layer (plate); $j=2=$ water layer; and $j=3$ $=$ seafloor layer (half-space). At $r=0$, and $z=h$ there is a spherical point source [Fig. 7(a)]. The solution for this boundary value problem was given by Ewing et al. (1957) in an integral form (also Aki and Richards 1980; White 1965). Here only the part of the solution for water is of interest

$$
\begin{aligned}
\phi_{2} & =2 \delta_{1} \int_{0}^{\infty} J_{0}(k r) \frac{\sin \nu_{1} h}{V}\left[S \cos \nu_{2}\left(z-H_{1}\right)\right. \\
& \left.-\sin \nu_{2}\left(z-H_{1}\right)\right] k d k
\end{aligned}
$$

where

$$
S=\frac{\delta_{2} \nu_{2} \tan \nu_{2} H_{2}-i \nu_{2}}{\delta_{2} \nu_{3}+i \nu_{2} \tan \nu_{2} H_{2}} \text { and } V=\delta_{1} \nu_{2} \sin \nu_{1} H_{1}+\nu_{1} S \cos n u_{1} H_{1}
$$

Here $H_{1}, H_{2}=$ thicknesses of layers 1 and $2 ; \delta_{1}=\rho_{1} / \rho_{2}$ and $\delta_{2}=\rho_{2} / \rho_{3} ; \rho_{1}, \rho_{2}, \rho_{3}=$ mass densities in layers $1,2,3 ; \nu_{j}=$ $\sqrt{k_{j}^{2}-k^{2}}=$ vertical wave number; $k_{j}=$ wave number in each layer; and $J_{0}(k r)=$ the zero-order Bessel function. Noting that $J_{0}(k r)=\left[H_{0}^{(1)}(k r)+H_{0}^{(2)}(k r)\right] / 2$, where $H_{0}^{(1)}$ and $H_{0}^{(2)}$ are Hankel functions of type (1) and (2), one obtains

$$
\begin{gathered}
\phi_{2}(z, r)=\frac{\delta_{1}}{2} \int_{-\infty}^{\infty} H_{0}^{(1)}(k r) \frac{\sin \nu_{1} h}{V}(S+i) e^{i \nu_{2}\left(z-H_{1}\right)} k d k \\
+\frac{\delta_{1}}{2} \int_{-\infty}^{\infty} H_{0}^{(2)}(k r) \frac{\sin \nu_{1} h}{V}(S-i) e^{-i \nu_{2}\left(z-H H_{1}\right)} k d k
\end{gathered}
$$

From the asymptotic expressions of Hankel functions (Watson 1966)

$$
H_{0}^{(1)} \cong \sqrt{\frac{2}{\pi r k}} e^{i(r k-\pi / 4)} \text { and } H_{0}^{(2)} \cong \sqrt{\frac{2}{\pi r k}} e^{-i(r k-\pi / 4)}
$$

Putting these expressions into (5), we change the integral to a standard form, which can be solved by the asymptotic expansion (Achenbach 1975)

$$
\phi_{2}(z, r)=\int_{-\infty}^{\infty} F_{1}(k) e^{i r f_{1}(k)} d k+\int_{-\infty}^{\infty} F_{2}(k) e^{i r_{2}(k)} d k
$$
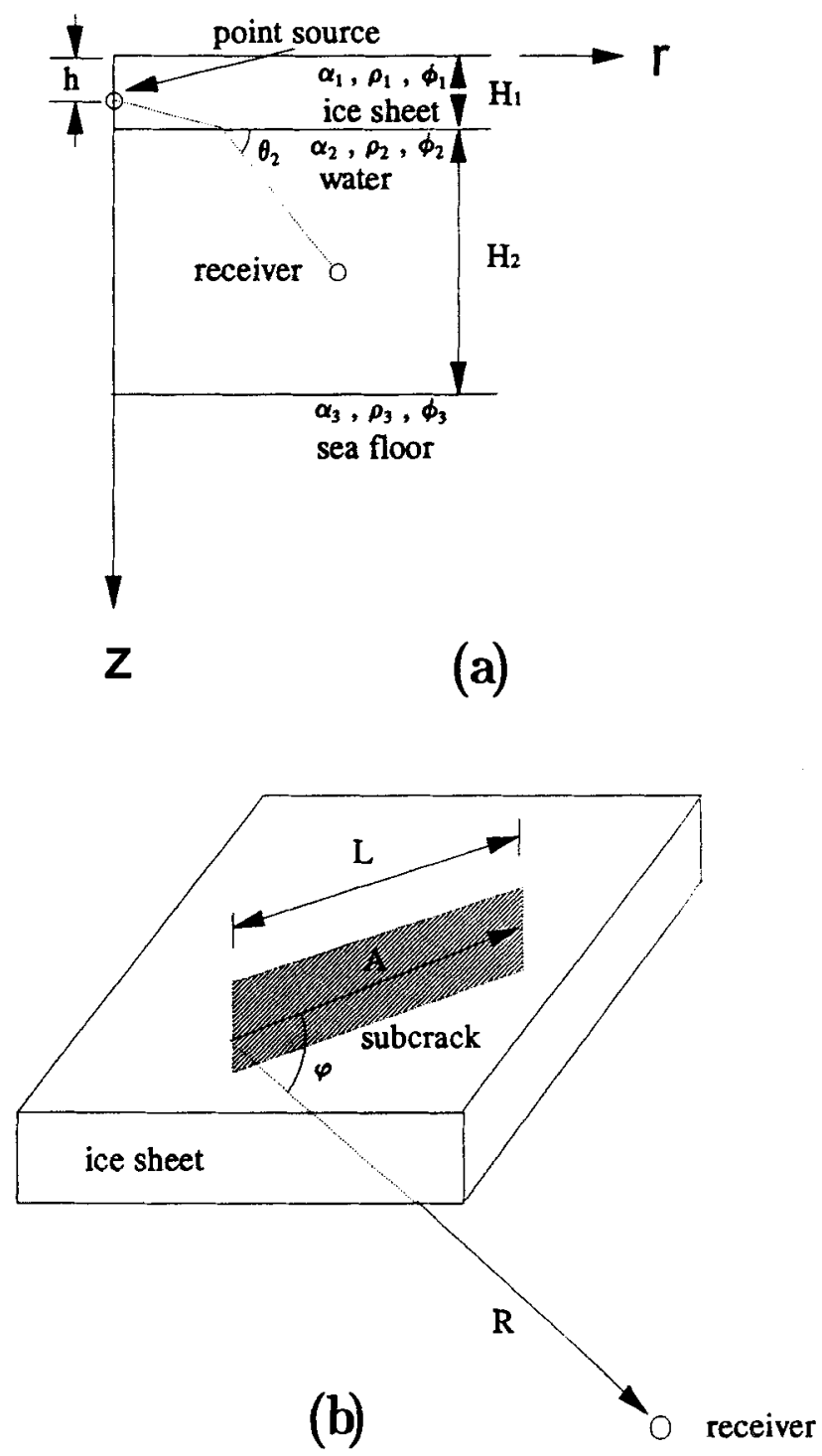

FIG. 7. (a) Three Layers in Ice-Water-Seafloor Model; (b) Crack Propagating in lce Sheet 
where

$$
\begin{gathered}
F_{1}(k)=\delta_{1} e^{\left.-i \mid \pi / 4+\nu_{1}\left(H_{1}-h\right)\right]} \sqrt{\frac{k}{2 \pi r}}(S+i) \frac{\sin \nu_{1} h}{V} \\
F_{2}(k)=\delta_{1} e^{i\left(\pi / 4+\nu_{1}\left(H_{1}-h\right)\right]} \sqrt{\frac{k}{2 \pi r}}(S-i) \frac{\sin \nu_{1} h}{V} \\
f_{1}(k)=k+\frac{1}{r}\left[\nu_{2}\left(z-H_{1}\right)+\nu_{1}\left(H_{1}-h\right)\right] / r, f_{2}(k)=-f_{1}(k)
\end{gathered}
$$

The point $k_{0}=k_{1} \cos \theta_{1}=k_{2} \cos \theta_{2}$ is found to be a stationary phase point, same as in Farmer and Xie's model; $\theta_{1}$ and $\theta_{2}$ are the refraction angles at the ice-water interface. The asymptotic solution of the integral is obtained as

$$
\phi_{2} \cong F_{1}\left(k_{0}\right) \sqrt{\frac{2 \pi}{f_{1}^{\prime \prime}\left(k_{0}\right)}} e^{i\left(\sigma_{1}\left(k_{0}\right)-\pi / 4\right)}+F_{2}\left(k_{0}\right) \sqrt{\frac{2 \pi}{f_{2}^{\prime \prime}\left(k_{0}\right)}} e^{k\left(f_{2}\left(k_{0}\right)+\pi / 4\right)}
$$

For a given point $(z, r)$, the solved $\phi_{2}$ is only a function of the wave numbers $k_{1}=\omega / \alpha_{1}, k_{2}=\omega / \alpha_{2}$, and $k_{3}=\omega / \alpha_{3}$. Actually, it is only a function of frequency $\omega$ if the wave velocities $\alpha_{1}$, $\alpha_{2}$, and $\alpha_{3}$ in the layers are given, namely, $\phi_{2}(z, r, k)=\phi_{2}(\omega)$.

The velocity potential for a given position of the point source can now be obtained. For a propagating crack source of length $L$ [Fig. 7(b)], the acoustic pressure $P(R, t)$ at $R=$ $\sqrt{r^{2}+(z-h)^{2}}$ can be obtained following a similar procedure as Farmer and Xie (1989)

$$
\begin{aligned}
& P_{2}(R, t)=\rho_{2}\left(\frac{\partial \Phi_{2}}{\partial t}\right) \\
& =\rho_{2} H_{1} \int_{0}^{L} \Phi_{2}^{\prime}\left[t-\frac{R}{c}-\frac{\xi}{c}\left(\frac{c}{v_{r}}+\cos \varphi\right)\right] d \xi \\
& =\frac{\rho_{2} L H_{1}}{\tau}\left[\Phi_{2}\left(t-\frac{R}{c}\right)+\Phi_{2}\left(t-\frac{R}{c}-\tau\right)\right]
\end{aligned}
$$

where $\tau=L\left(c / v_{r}+\cos \varphi\right) / c=$ time delay; and $c=$ average acoustic velocity. Then the Fourier spectrum of the pressure is
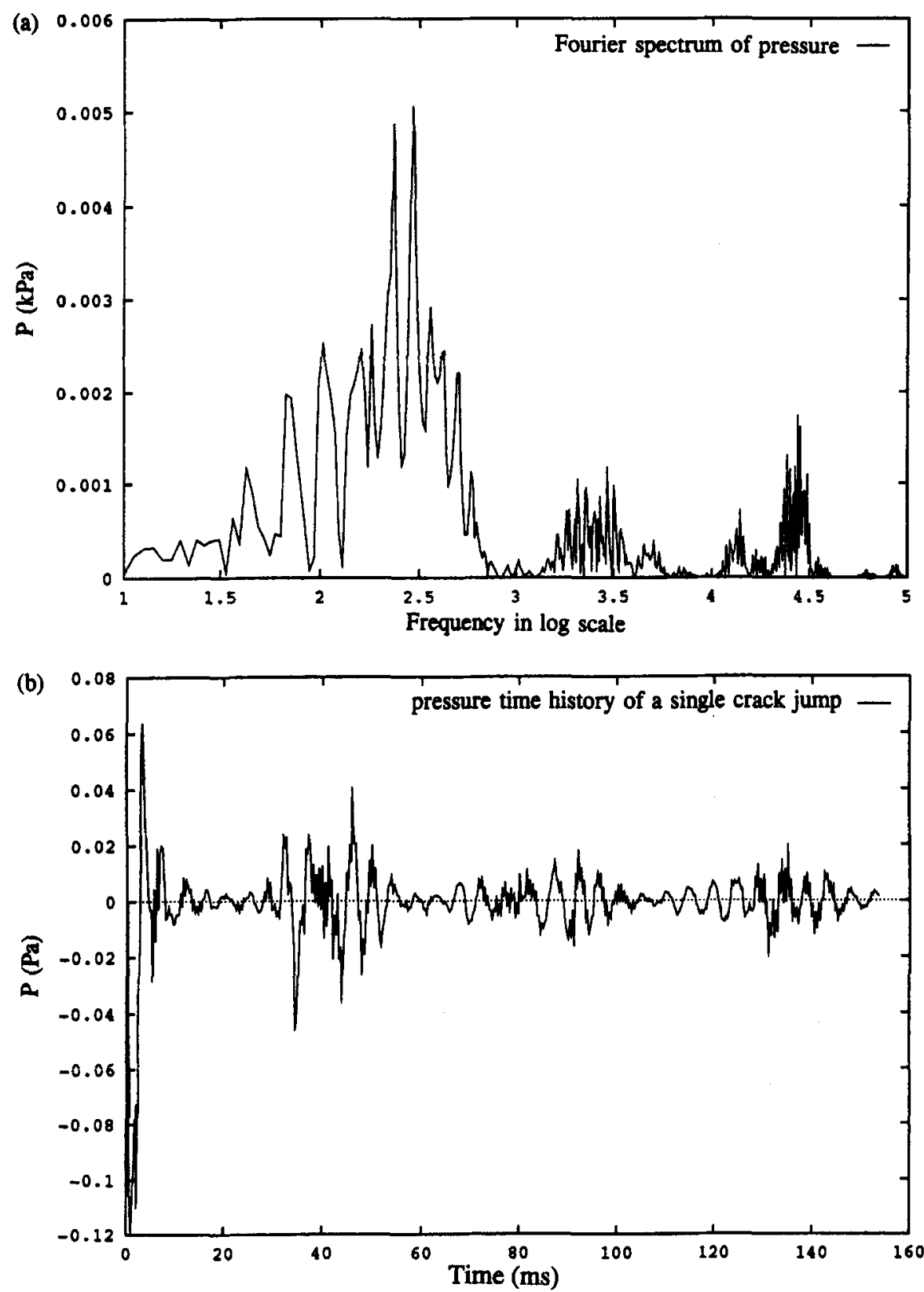

FIG. 8. (a) Fourler Spectrum for Single Crack by Modifled Farmer-Xle's Model; (b) Acoustic Pressure SIgnal In TIme Domain by ModIfled Model 


$$
\bar{P}_{2}(\omega)=\rho_{2} L H_{1} U_{s}(\omega) \phi_{2}(\omega) e^{-i \omega(R / c)}\left(1-e^{-i \omega \tau}\right)
$$

where $v_{r}=$ crack velocity; and $U_{s}(\omega)=$ source strength with a roughened function

$$
G(t)= \begin{cases}0 & t<0 \\ \frac{1}{T}\left(t-\varepsilon \frac{\sin (2 n \pi t / T)}{2 n \pi / T}\right) & 0 \leq t \leq T \\ 1 & t>T\end{cases}
$$

which was given by Haskell (1964) in the context of mechanics of earthquakes; here $T=L v_{r}$, which is different from Farmer and Xie's model. For $U_{s}(t)=D_{0} G^{\prime}(t)$, the corresponding Fourier spectrum is

$$
U_{s}(\omega)=D_{0} e^{i \omega T / 2} \frac{\sin (\omega T / 2)}{\omega T / 2} \frac{1-(1-\varepsilon)(\omega T / 2 n \pi)^{2}}{1-(\omega T / 2 n \pi)^{2}}
$$

where $\varepsilon=$ roughening amplitude; $n=$ roughening frequency; and $D_{0}=$ amplitude of the source displacement, which can be calculated directly from the particle system fracture simulation.

All the parameters in the present modification of Farmer and Xie's model for a three-layer half-space can be determined from the material properties of the interparticle links and from the solution of fracture propagation in the random particle system. For each crack jump, the Fourier spectrum of the pressure history of the acoustic wave can be obtained by means of inverse Fourier transform. The Fourier spectrum $\tilde{P}_{2}(\omega)$ can be

(a)
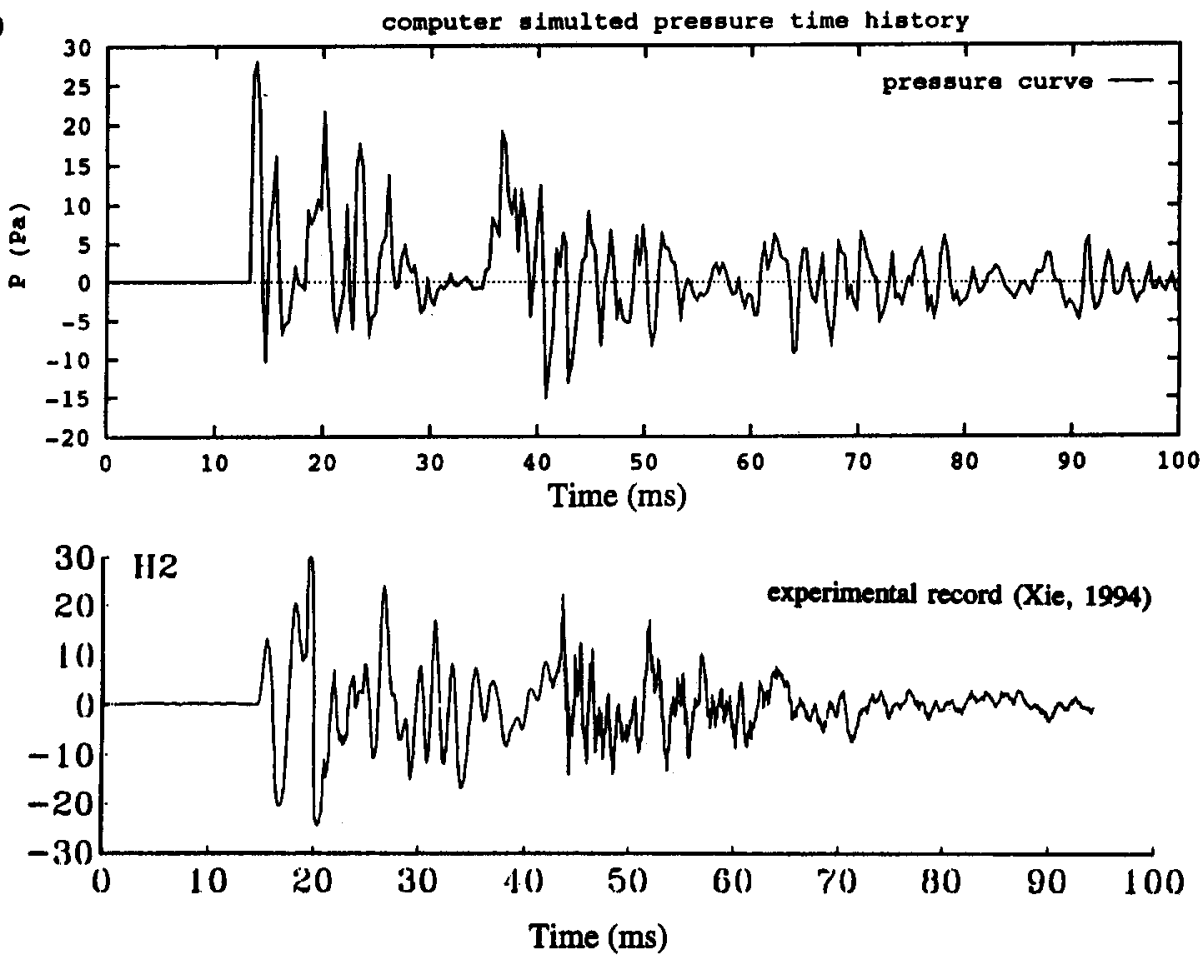

(b)
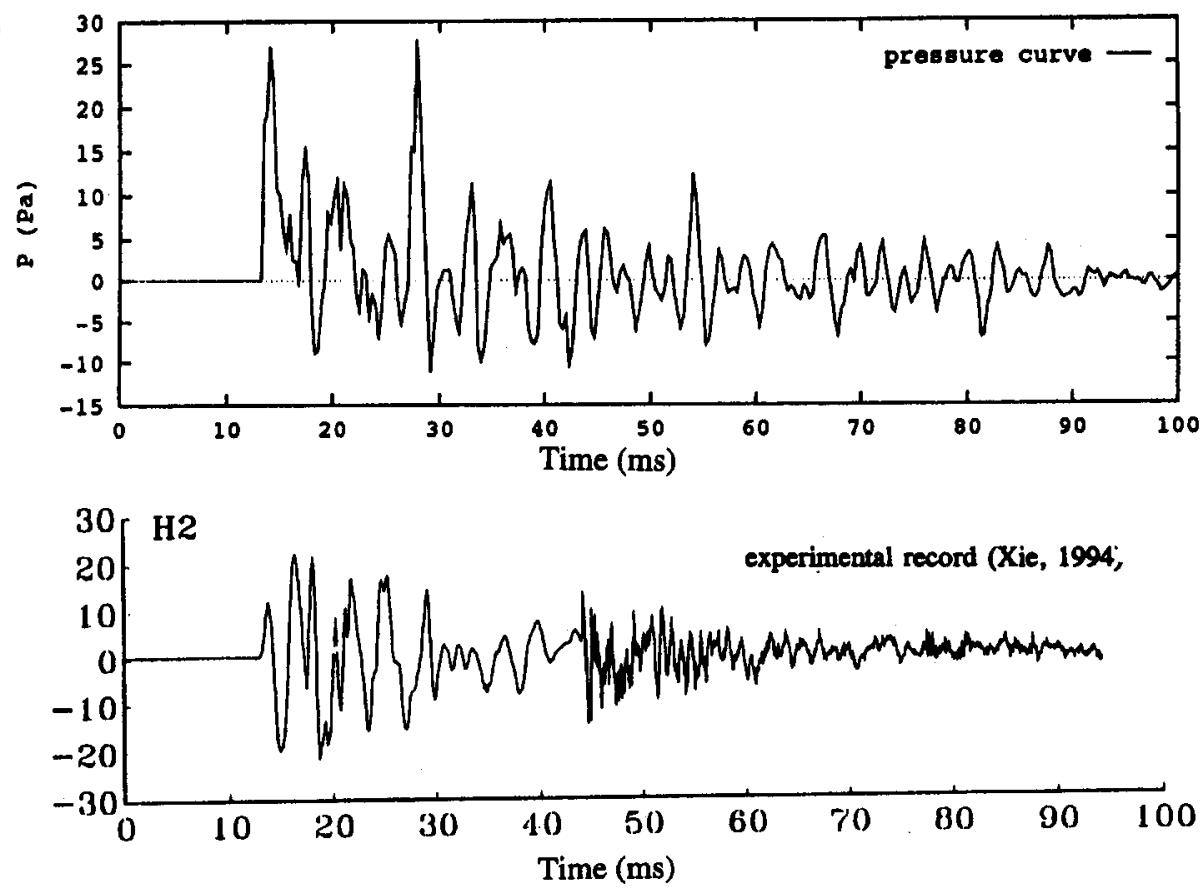

FIG. 9. (a) Simulated Acoustic Pressure Signal History; (b) Experimental Record for Initial Crack on $30 \mathrm{~m} \times 30 \mathrm{~m}$ Ice Specimen 
converted to the acoustic signal in the time domain, $P_{2}(R, t)$ $=\mathscr{F}^{-1}\left[P_{2}(\omega)\right]$, in which $\mathscr{F}^{-1}$ is the inverse Fourier transform. The acoustic signals of all the cracks in the ice fracture process, which are calculated by the particle model, are superimposed in time, that is

$$
P(R, t)=\sum_{i=1}^{n} P_{i}\left(R_{i}, t_{i}+\tau\right), \quad \tau \geq 0
$$

This superposition makes the acoustic signals more complicated and realistic.

As an example for our modification of Farmer and Xie's model, Fig. 8(a) shows the Fourier spectrum of a single crack jump with crack length $L=1.2 \mathrm{~m}$ and Fig. 8(b) shows the corresponding pressure signal in the time domain. Compared with the original Farmer and Xie's model, the Fourier spectrum for the present modification of model is a little rough. It also exhibits some dominant frequencies. They are caused by the third layer and by the fact that the wave in water has some preferred frequencies because of the multiple reflections. In the time domain [Fig. 8(b)], some wave clusters due to multiple reflections appear, which means the modified model includes the $R$-wave. The calculations also verify that the modified model can degenerate to the original Farmer and Xie's model when the material constants of the seafloor and of the water are taken to be equal.

One limitation of the modified model is that the Fourier spectrum is constant throughout the crack propagation although it is varying in the experimental record (Xie 1994). Another limitation is that the model considers the linear acoustic wave only. In consequence, the $F$-wave cannot be fully expressed and there is no Crary phase, which is related to the seismic waves. Anyway, the $F$-wave is a small contribution to the acoustic emission record. As a linear approximation of the acoustic emission, the present modification of Farmer and Xie's model can describe the major part of the acoustic signals.

\section{INFLUENCE OF MODEL PARAMETERS, COMPARISON WITH ACOUSTIC RECORDS AND SIZE EFFECT}

One of the most important parameters is the length $L$ of the individual cracks jumps. The present study shows that the strength of the acoustic signal source depends on the size of the source volume and the amplitude of the crack moving velocity, which decide the energy released from the crack jump. In the simulation, the length of each crack jump is taken the same as the length of the broken link, which is a random value between 0.75 and $1.5 \mathrm{~m}$. The energy radiated by each crack jump depends on the microfracture energy required to break the interparticle link and thus on the interparticle strength and ductility $\varepsilon_{f} / \varepsilon_{p}$, as well as the statistical coefficients of variation of these parameters.

A comparison of the calculated and measured acoustic signals is given in Figs. $9(a$ and $b)$ for specimen size $30 \times 30$ $\mathrm{m}$. Fig. 10( $\mathrm{a}$ and $\mathrm{b})$ compares the mean squares of these signals over time interval $\hat{T}$, defined as $\bar{T}^{-1} \int_{0}^{\hat{T}} P(t)^{2} d t$, which is proportional to the mean power of the signal over interval $T$. From these figures, it can be seen that the simulated signals have less power than the recorded signals although the maximum magnitudes of the pressure are very close. This is caused by the linear wave simplification in the simulation, which causes the loss of some of the wave components.

Figs. 11 and 12 show the simulated pressure signals for the $12 \times 12 \mathrm{~m}$ and $3 \times 3 \mathrm{~m}$ size floes. The amplitudes are not much smaller than those from the $30 \times 30 \mathrm{~m}$ floe, because the receiver is closer to the crack. To compare the signal amplitudes for the specimens of different sizes, the source-receiver distance needs to be normalized to a certain value.

Fig. 13 compares the root-mean-square (RMS) values $\sqrt{\bar{T}^{-1} \int_{0}^{\bar{T} P(t)^{2}} d t}$ of the pressure signals for different sizes $(\bar{T}$ $=12 \mathrm{~ms}$ is used). The RMS has the dimension of pressure. This comparison reveals that the RMS of the acoustic pressure signals exhibits size differences.

An interesting question is whether the differences in acous-
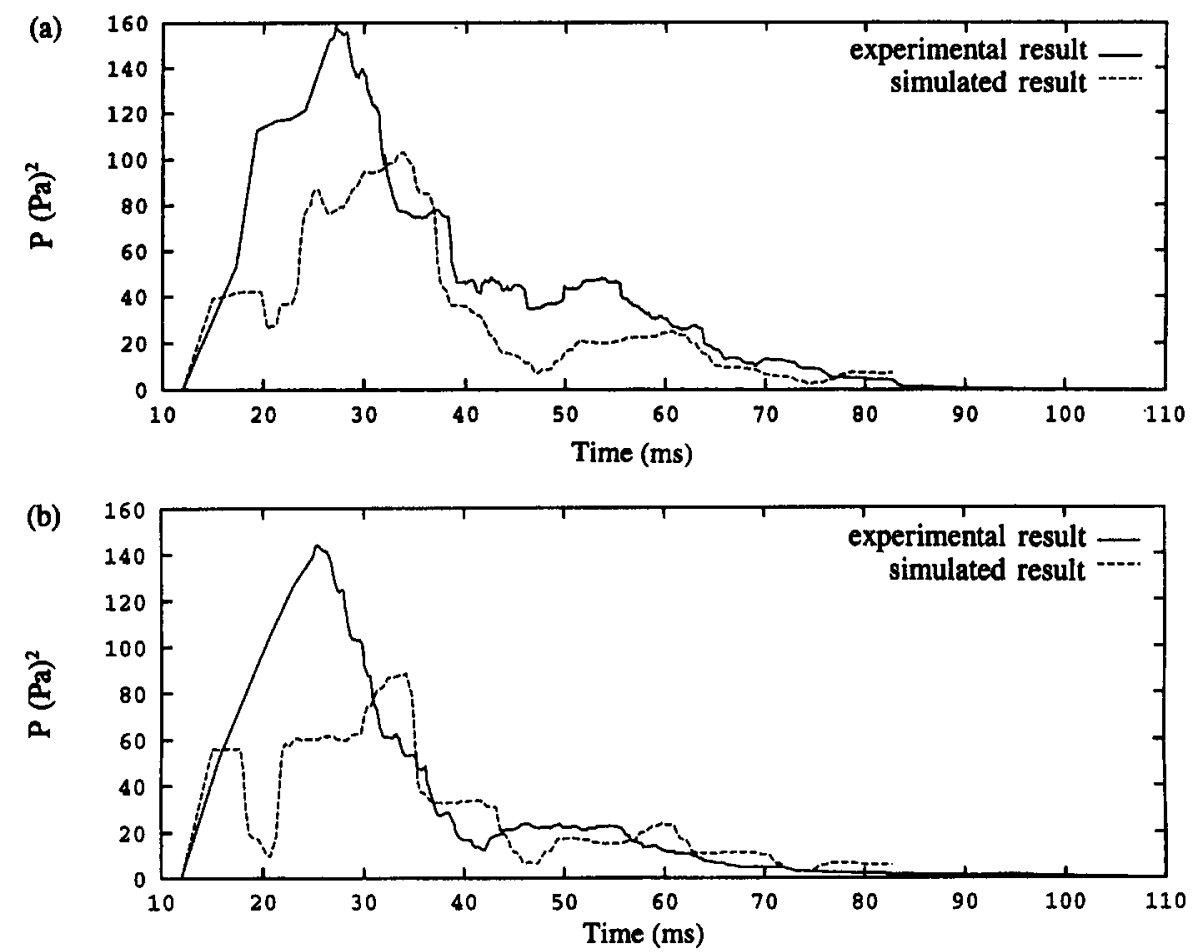

FIG. 10. Two Examples of Comparison of Simulated Pressure Mean Square History with Experimental History (for $30 \mathrm{~m} \times 30 \mathrm{~m}$ Ice Specimen) 


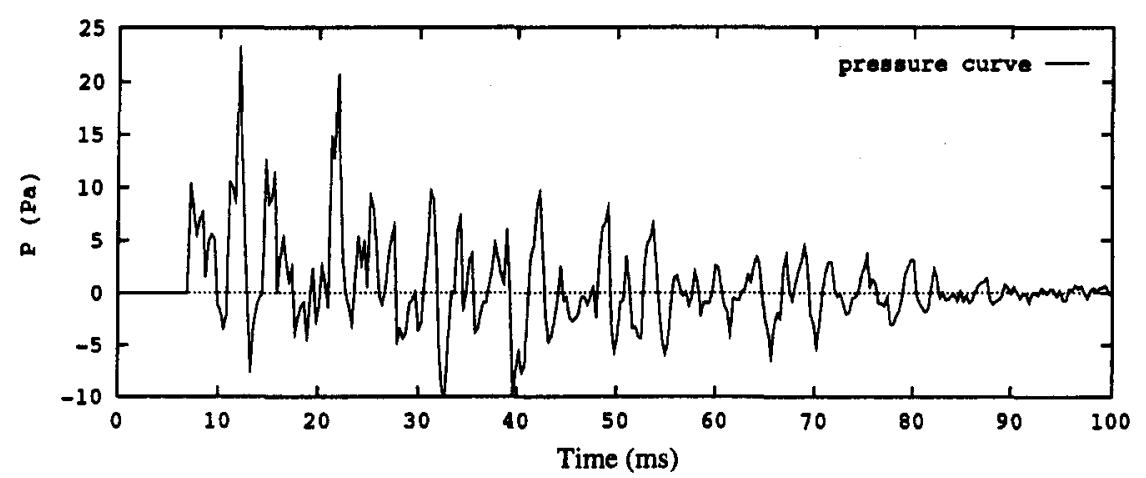

FIG. 11. Simulated Acoustic Pressure Signal for Initial Crack In $12 \mathrm{~m} \times 12 \mathrm{~m}$ Ice Specimen
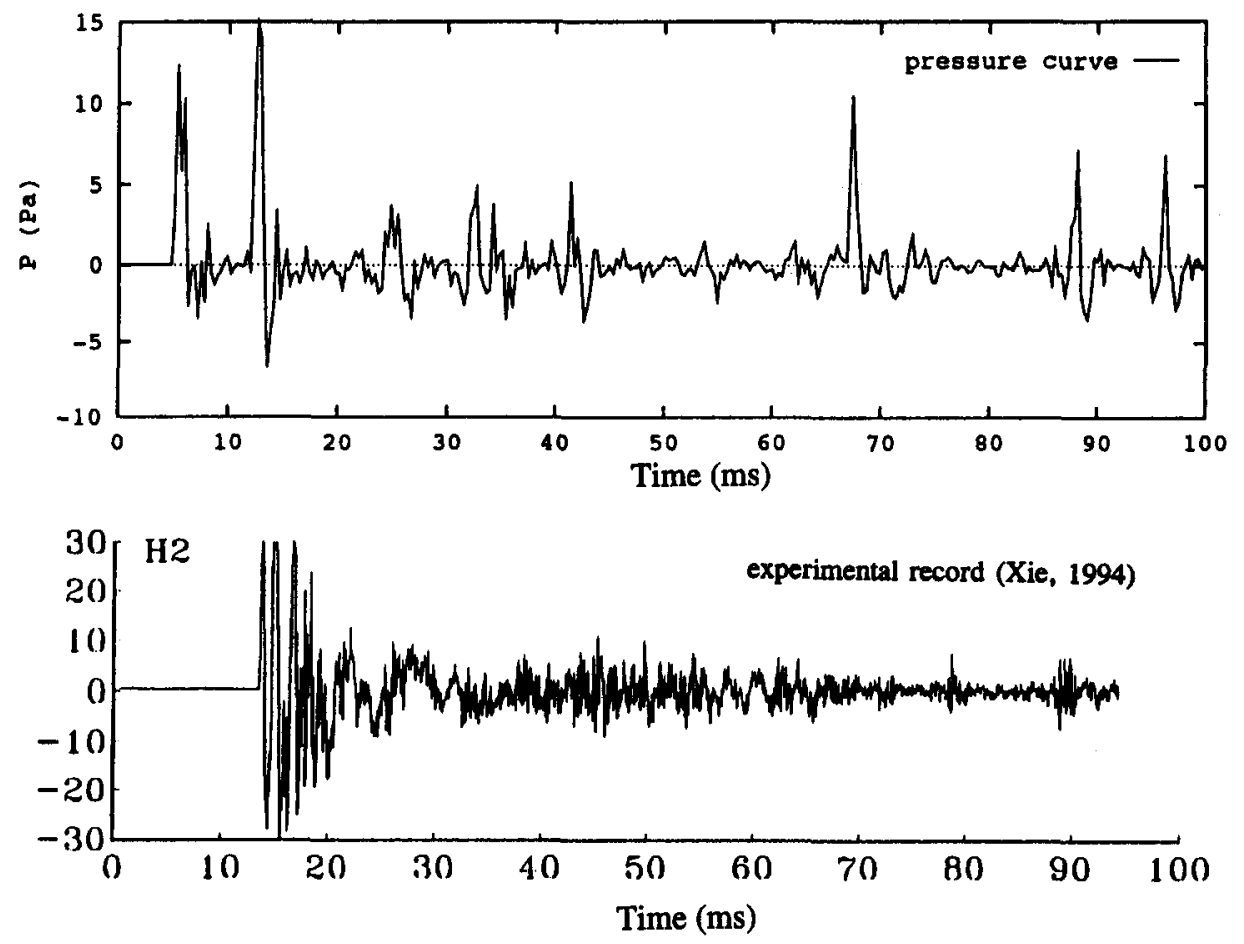

FIG. 12. (a) Simulated Acoustlc Pressure, Compared to (b) Experimental Record for Initial Crack on $3 \mathrm{~m} \times 3 \mathrm{~m}$ Ice Specimen

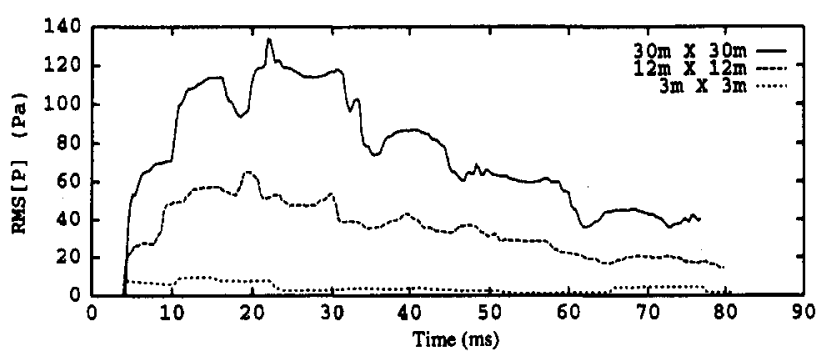

FIG. 13. Size Effect on Acoustic Emission Root-Mean-Square (RMS) Pressure History

tic records such as those in Fig. 13 could be exploited for inferring the characteristics of particle system, such as the microfracture energy $G_{f}^{m}$ and the mean particle spacing $\bar{L}$. One could make various choices of these values and simulate for each choice the acoustic signals. Then one could identify the choice for which the match is optimum. Based on the experience with identifying the material fracture characteristics from the measured load-deflection curves and maximum loads, this approach would not be likely to succeed if only a few acoustic records for fractures of similar length were available. But it could succeed if the acoustic records were available for fractures of very different lengths. Of course it would also be useful to have records of acoustic signals at different locations, making it possible to determine the locations of the acoustic sources. At present there are insufficient data to explore these interesting questions and further study is desirable.

\section{SUMMARY AND CONCLUSIONS}

1. The random particle model (discrete element method) can be used to simulate the ice sheet fracture process. The inhomogeneity of ice can be represented by the randomly distributed particle mesh. The "jump-arrest" phenomenon in ice fracture can be described by the breaks of individual interparticle links.

2. Acoustic records similar to those recorded in experiments can be generated with the model. Differences among the acoustic records for different fracture lengths offer the possibility of identifying the fracture characteristics of sea ice from the acoustic records.

3. A three-layer modification of Farmer and Xie's model is presented to generate the acoustic signals from a propagating crack source, and asymptotic solutions are obtained for the $A$-wave, $R$-wave, $P$-wave, and $F$-wave. By superposition of the acoustic signals from each crack jump, a linearized acoustic wave in time domain can be synthesized by inverse Fourier transform. To simplify and linearize the model, the $F$-wave, which makes a minor contribution, can be omitted. 
4. An effect of specimen size on the RMS of pressure record is revealed by the particle system simulation. Its meaning and application in identifying ice plate characteristics and fracture properties from acoustic records deserve further study.

\section{APPENDIX. REFERENCES}

Achenbach, J. D. (1975). Wave propagation in elastic solids. North-Holland Publishing Co., Amsterdam, The Netherlands.

Adamson, R. M., Dempsey, J. P., DeFranco, S. J., and Xie, Y. (1995). "Large-scale in-situ ice fracture experiments - Part I: Experimental aspects." Ice mechanics - 1995, J. P. Dempsey and U. D. S. Rajapakse, eds., vol. 207, American Society of Mechanical Engineers, New York, N.Y., $107-128$.

Aki, K., and Richards, P. G. (1980). Quantitative seismology theory and methods. W. H. Freeman and Co., San Francisco, Calif.

Bažant, Z. P. (1992a). "Large-scale fracture of sea ice plates." Proc., 11th IAHR Ice Symposium, Vol. 2 (held in Banff, Alberta), ed. by T. M. Hrudey, University of Alberta, Edmonton, Alberta, Canada, 991 1005 .

Bažant, Z. P. (1992b). "Large-scale thermal bending fracture of sea ice plates." J. Geophys. Res., 97(C11), 17739-17751.

Bažant, Z. P., and Kim, Jenn-Keun. (1985). "Fracture theory for nonhomogeneous brittle materials with application to ice." Proc., ASCE Nat. Conf. on Civ. Engrg. in the Arctic Offshore-ARCTIC 85, ASCE, New York, N.Y., 917-930.

Bažant, Z. P., Kim, J.-J., and Li, Y.-N. (1995a). "Part-through bending cracks in sea ice plates: mathematical modeling." in AMD-Vol. 207, Ice mechanics, ASME, Summer Meeting, Los Angeles, CA, ed, by J. P. Dempsey and Y. Rajapakse, 97-105.

Bažant, Z. P., Tabbara, M. R., Kazemi, M. T., and Pijandier-Cabot, G. (1990). "Random particle model for fracture of aggregate or fiber composites." J. Engrg. Mech., ASCE, 116(8), 1686-1705.

Bažant, Z. P., and Li, Y.-N. (1993). "Fracture analysis of penetration through floating sea ice plate and size effect." Proc., Ist Joint Mech. Meeting of ASME-ASCE-SES (Meet'n'93), held in Charlottesville, VA., ed. by J. P. Dempsey, Z. P. Bažant, Y. D. S. Rajapakse, and S. Shyam Sunder, University of Virginia, Charlottesville, 131-144.

Bažant, Z. P., and Li, Y.-N. (1994). "Penetration through floating sea ice plate and size effect: simplified fracture analysis." J. Engrg. Mech., ASCE, 120(6), 1304-1321.

Bažant, Z. P., and Li, Y.-N. (1995). "Penetration fracture of sea ice plate." Int. J. Solids and Struct. 32(3/4), 303-313.

Bažant, Z. P., Li, Y.-N., Jirásek, M., Li, Z., and Kim, J.-J. (1995b). “Effect of size on distributed damage and fracture of sea ice." Proc., Sea Ice Mech. and Arctic Modeling Workshop, Anchorage, Alaska, Org. by Northwest Res. Assoc., Bellevue, WA, sponsored by Office of Naval Research, 73-83.

Cundall, P. A. (1971). "A computer model for simulating progressive large-scale movements in blocky rock systems." Proc., Int. Symp. on Rock Fracture, ISRM, Nancy, France, 2-8.

Cundall, P. A., and Strack, O. D. L. (1979). "A discrete numerical model for granular assemblies." Geotechnique, 29, 47-65.

Dempsey, J. P. (1996). "Scale effects on the fracture of ice." The Johannes Weertman Symposium. R. J. Arsenault, D. M. Cole, T. Gross,
G. Kostorz, P. Liaw, S. Parameswaran, and H. Sizek, eds., Cold Regions Res. and Engrg. Lab., U.S. Army, Hanover, NH, 351-361.

Dempsey, J. P., Adamson, R. M., and Mulmule, S. V. (1995). "Largescale in-situ fracture of ice." Fracture mechanics of concrete structures, Proc., 2nd Int. Conf. on Fracture Mech. of Concrete and Concrete Structures (FraMCoS-2), held at ETH, Zürich, ed. by F. H Wittmann, ed., Aedificatio Publishers, Freiburg, Germany, 675-684.

Dempsey, J. P., et al. (1991). "Fracture resistance to cracking in ice: initiation and growth." Proc., ASCE 6th Int. Spec. Conf. on Cold Regions Engrg., American Society of Civil Engineering, New York, N.Y., 579-594.

Dempsey, J. P., Wei, Y., and DeFranco, S. J. (1992). "Notch sensitivity and brittleness in fracture testing of s2-columnar fresh-water ice." Int. J. Fracture, 53(2), $101-120$.

Dempsey, J. P., and Zhao, Z. C. (1993). "Elastohydrodynamic response of an ice-sheet to forced subsurface uplift." J. Mech. Phys. Solids, 41(3), 487-506.

Ewing, W. M., Jardetzky, W. S., and Press, F. (1957). Elastic waves in layered media. McGraw-Hill, Inc., New York, N.Y.

Farmer, D. M., and Xie, Y. (1989). "The sound generation by propagating cracks in sea ice." J. Acoust. Soc. Am., 85(4), 1489-1500.

Haskell, N. A. (1964). "Total energy and energy spectral density of elastic wave radiation from propagating faults." Bull. of the Seismological Soc. of Am., 54(6), $1811-1841$.

Jirásek, M., and Bažant, Z. P. (1993). "Discrete element modeling of fracture and size effect in quasibrittle materials: Analysis of sea ice." Proc., held at M.I.T., 2nd Int. Conf. on Discrete Element Methods (DEM), March, J. R. Williams and G. G. W. Mustoe, eds., IESL Publications, 357-368.

Jirásek, M., and Bažant, Z. P. (1995a). "Particle model for quasibrittle fracture and application to sea ice." J. Engrg. Mech., ASCE, 121(9), 1016-1025.

Jirásek, M., and Bažant, Z. P. (1995b). "Macroscopic fracture characteristics of random particle systems." Int. J. Fracture, 69(3), 201-228.

Li, Y. N., and Bažant, Z. P. (1994). "Penetration fracture of floating iceplate: 2D analysis and size effect.' J. Engrg. Mech., ASCE, 120(7), $1481-1498$.

Mulmule, S. V., Dempsey, J. P., and Adamson, R. M. (1995). "Large scale in-situ ice fracture experiments - Part II: modeling aspects." Ice mechanics - 1995, J. P. Dempsey and Y. D. S. Rajapakse, eds., Am. Soc. of Mech. Engrs., AMD-Vol 207, 129-146.

Press, F., and Ewing, W. M. (1951). "Propagation of elastic waves in a floating ice sheet." Trans. Am. Geol. Union., 32, 673-678.

Stein, P. J. (1988). "Interpretation of a few ice event transients." $J$. Acoust. Soc. Am., 83(2), 617-622.

Watson, G. N. (1966). A treatise on the theory of Bessel functions. The University Press, Cambridge, U.K., 198.

White, J. E. (1965). Seismic waves: radiation, transmission, and attenuation. McGraw-Hill, Inc., New York, N.Y.

Xie, Y. (1994). "The sensing of ice failure processes through acoustic and seismic emissions from developing fracture." Report, University of British Columbia, J. Acoust. Soc. Am.,

Xie, Y., and Farmer, D. M. (1989). "Acoustic radiation from thermally stressed sea ice." J. Acoust. Soc. Am., 89(5), 2215-2231.

Xie, Y., and Farmer, D. M. (1994). "Seismic-acoustic sensing of sea ice wave mechanical properties." J. Geophys. Res., 99(C4), 7771-7786.

Zubelewicz, A., and Bažant, Z. P. (1987). "Interface element modeling of fracture in aggregate composites." J. Engrg. Mech., ASCE, 113(1), 1619-1630. 